\title{
Programa Nacional de Biodiesel e Agricultura Familiar em Mato Grosso
}

\author{
Marcos Rodrigues ${ }^{1}$ \\ Arturo Alejandro Zavala Zavala ${ }^{2}$
}

\begin{abstract}
Resumo
O Programa Nacional de Produção e Uso de Biodiesel não somente marcou o início da produção de biodiesel no Brasil, como também introduziu a participação da agricultura familiar no processo. O Mato Grosso hoje é o principal produtor de biodiesel no país e, a partir deste ponto, este trabalho buscou verificar como o Programa foi capaz de integrar a agricultura familiar no estado. Através da pesquisa com produtores rurais no Norte do estado de Mato Grosso foi estimado um modelo econométrico por MQO para verificar quais fatores contribuem para a geração de renda na agricultura familiar. Observou-se que a produção de soja é predominante e possui maiores rendimentos principalmente com a área disponível para cultivo, enquanto que fatores como experiência e crédito não influenciam significativamente, mas mesmo com as limitações existentes para a soja na agricultura familiar, é possível atingir o objetivo do programa de geração de renda, mas não vem sendo eficiente em facilitar o acesso a este mercado pela agricultura familiar.
\end{abstract}

Palavras-chaves: Agricultura Familiar, Biodiesel, Desenvolvimento Rural.

\section{National Program of Biodiesel and Family Farming in Mato Grosso}

\begin{abstract}
The National Program of Production and Use of Biodiesel not only marked the beginning of the production of biodiesel in Brazil, but also introduced the family farming in the process. The Mato Grosso state is now the largest producer of biodiesel in the country, and from this point, this study sought to ascertain how the Program was able to join the family farming in the state. Through research with farmers in the northern state of Mato Grosso an econometric model was estimated by OLS to determine what factors contribute to income generation in family farming.It was observed that soybean production is predominant and has higher income mostly with the area available for cultivation, while factors such as experience and credit do not have significantly influence, but even with the existing limitations for soybeans in family farming, it is possible to achieve the purpose of income generation program, but is not efficient to facilitate access to this market by family farmers.
\end{abstract}

Keywords: Family farming, Biodiesel, Rural Development.

\section{INTRODUÇÃO}

\footnotetext{
1 Mestre em Agronegócios e Desenvolvimento Regional (UFMT). Doutorando em Desenvolvimento Socioambiental (UFPA). marcos.rodrigues.adm@gmail.com

${ }^{2}$ Doutorado em Estatística pela Universidade de São Paulo. Atualmente é professor adjunto IV da Universidade Federal de Mato Grosso. arturoz@ig.com.br
} 
A produção de biodiesel no Brasil teve início oficial a partir do ano de 2005 através da implementação do Programa Nacional de Produção e Uso do Biodiesel (PNPB). Além de atender a uma questão ambiental em relação à substituição parcial do uso de combustíveis fósseis e oferecer uma nova possibilidade para suprir a demanda energética no país, o Programa articulou uma base social através da produção de matéria-prima pela agricultura familiar.

O óleo de soja e o sebo bovino hoje são os principais produtos utilizados como matéria-prima para a produção de biodiesel (ANP, 2014). A soja no contexto mato-grossense é uma cultura de alto grau de modernização (ANDERSEN et al., 2002), onde grandes volumes de capital são aplicados (seja na forma de insumos ou de produtos e equipamentos agrícolas), levando a uma redução na taxa de lucro que deve ser superada pelo aumento extensivo da produção (ganhos de escala). Tal situação vai em oposição as características da pequena produção, baseada no trabalho familiar, menor investimento em capital e atividades que não dependem do ganho de escala. A produção de soja para ser viabilizada nestes moldes requer uma mudança de paradigma dentro da estrutura produtiva de commodities em Mato Grosso.Assim fica estabelecido um problema para a cadeia de biodiesel: estaria o Programa Nacional de Produção e Uso de Biodiesel realmente sendo capaz de cumprir sua função social em integrar a agricultura familiar no fornecimento de matérias-primas conforme planejado e ao mesmo tempo manter um ambiente competitivo entre as usinas produtoras?

Como objetivo deste artigo é proposto avaliar os aspectos determinantes na geração de renda pela produção de matéria-prima na agricultura familiar em Mato Grosso. A hipótese estabelecida é de que a integração da agricultura familiar ocorre de forma parcial dado às características do mercado de commodities no estado, entretanto vem apresentando sucesso em relação à geração de renda para estas famílias já integradas na cadeia produtiva.

Além desta breve introdução o artigo está estruturado em outras 4 seções. A segunda seção desenvolve a evolução da produção de biodiesel dentro das cadeias agroindustriais no Brasil e o papel da agricultura familiar neste contexto. A terceira seção apresenta a metodologia para na quarta seção serem tecidas as discussões a partir dos resultados obtidos. Por fim é realizada uma conclusão a partir do objetivo proposto neste trabalho.

\section{PRODUÇÃO DE BIODIESEL E AGRICULTURA FAMILIAR NO BRASIL}

\subsection{O Complexo Agroindustrial no e a Produção de Biodiesel}


A produção agrícola envolve uma série de agentes distintos, mas interligados cada vez mais através do arranjo institucional desenvolvido pelas suas relações de comercialização. Batalha e Silva (2011) colocam que a produção agrícola não pode mais ser tratada em questão de agentes individuais, mas sob toda a cadeia produtiva, que engloba desde a produção, a transformação a distribuição e o consumo. Este arranjo, denominado de complexo agroindustrial, tem inicio desde a produção da matéria prima agrícola (inclusive pelo setor anterior a produção como o fornecimento de equipamentos e insumos) até as diversas formas de processamento e beneficiamento desta matéria-prima.

As empresas do complexo agroindustrial, denominadas aqui como tradings, detém uma parcela considerável da produção de soja do estado de Mato Grosso através do seu sistema de financiamento a produção, atrelado à venda do produto em data certa (RODRIGUES; MARQUEZIN, 2014). Esta verticalização da cadeia permite ajustar o fornecimento da produção agrícola, em data, quantidade e qualidade certas, criando uma sinergia entre estes diversos atores. O resultado é que a verticalização do agronegócio permitiu a redução dos custos de transação com a elaboração de contratos pré-determinados com os produtores rurais (os quais seguem padrões de produção, qualidade e quantidade devidamente orientadas) e com fornecimento para o setor consumidor (produtos de forma massificada em processo industrial).

O complexo agroindustrial do biodiesel tem em sua cadeia a agroindústria de óleo vegetal como intermediário entre a matéria prima e a produção de biodiesel, responsável pela produção do óleo vegetal (LIMA; CASTRO, 2010). Entretanto a própria agroindústria de óleo vegetal também pode ser a indústria de produção de biodiesel (e mais, pode ser até mesmo a fornecedora de insumos), controlando desta forma uma parte considerável da cadeia produtiva.

O considerável aumento da emissão de poluentes, principalmente pela queima de combustíveis fósseis (petróleo, gás natural, carvão), consideradas os principais causadores de danos ambientais, como o aquecimento global. Tal situação se agravou com o aumento da produção industrial que também acelerou a emissão destes poluentes devido ao uso mais intensivo de energia, provocando questionamentos quanto à sustentabilidade do modelo produtivo. Portanto neste cenário os biocombustíveis, aqui neste trabalho restrito ao biodiesel, ganharam espaço na produção energética pelo fato de serem renováveis e menos poluentes devido a compensação de carbono pela utilização de matérias-primas oriundas da biomassa, (HOUTART, 2010).

O biodiesel foi introduzido na matriz energética brasileira a partir da promulgação da lei $\mathrm{n}^{\mathrm{o}}$ 11.097, de 13 de janeiro de 2005. Ficou estabelecido que o percentual mínimo a ser 
adicionado ao diesel, após três anos da publicação da legislação, seria de $2 \%$ em volume, subindo este percentual para $5 \%$ até o final de oito anos. O PNPB foi capaz, de em janeiro de 2010 já ter sido a marca de adição de 5\% de biodiesel ao diesel, três anos antes do previsto. Em julho de 2014 o percentual subiu para 6\% e depois em novembro para 7\%. A Tabela 1 demonstra a evolução da produção para as regiões brasileiras desde a implantação do PNPB.

Tabela 1: Evolução da produção de Biodiesel (B100) nas regiões brasileiras e no Brasil (mil $\left.m^{3}\right)-2005$ a 2013.

\begin{tabular}{lrrrrrrrrr}
\hline Região & $\mathbf{2 0 0 5}$ & $\mathbf{2 0 0 6}$ & $\mathbf{2 0 0 7}$ & $\mathbf{2 0 0 8}$ & $\mathbf{2 0 0 9}$ & $\mathbf{2 0 1 0}$ & $\mathbf{2 0 1 1}$ & $\mathbf{2 0 1 2}$ & $\mathbf{2 0 1 3}$ \\
\hline Brasil & 0,74 & 69,00 & 404,33 & $1.167,13$ & $1.608,45$ & $2.386,40$ & $2.672,76$ & $2.717,48$ & $2.917,49$ \\
Norte & 0,51 & 2,42 & 26,59 & 15,99 & 41,82 & 95,11 & 103,45 & 78,65 & 62,24 \\
Nordeste & 0,16 & 34,80 & 172,20 & 125,91 & 163,91 & 176,99 & 176,42 & 293,57 & 278,38 \\
Sudeste & 0,04 & 21,56 & 37,02 & 185,59 & 284,77 & 420,33 & 379,41 & 255,73 & 261,37 \\
Sul & 0,03 & 0,10 & 42,71 & 313,35 & 477,87 & 675,67 & 976,93 & 926,61 & $1.132,41$ \\
Centro- & 0,00 & 10,12 & 125,81 & 526,29 & 640,08 & $1.018,30$ & $1.036,56$ & $1.162,91$ & $1.183,09$ \\
Oeste & & & & & & & & & \\
\hline
\end{tabular}

Fonte: ANP (2014).

A concentração da produção se percebe principalmente nas regiões Sul, destacando o Rio Grande do Sul, e na região Centro-Oeste, principalmente nos estados de Goiás e Mato Grosso. Estas duas regiões representaram juntas 79,37 \% da produção nacional em 2013. Um fator de grande importância para este desenvolvimento da produção nestas regiões é a presença da matéria-prima em grandes quantidades, principalmente no caso da soja, onde o Mato Grosso é o maior produtor do país (OSAKI; BATALHA, 2011).

Como proposta inicial, o PNPB procurou estimular a diversificação das matériasprimas que seriam utilizadas para a produção de biodiesel, ação que permitiria maior integração da agricultura familiar por oferecer mais oportunidades para atingir o objetivo de geração de renda (HOLANDA, 2003). Concentrando-se nos estados produtores de soja, o biodiesel acabou assimilando como principal matéria-prima a soja, pela sua grande disponibilidade nestas regiões, o que leva a questionar a real capacidade do programa em integrar a pequena produção em um mercado já desenvolvido e operante sobre outros paradigmas. A composição percentual da produção de biodiesel em novembro de 2014 é demonstrada na Tabela 2 . 
Tabela 2: Composição da produção de biodiesel (b100) por Região do país Novembro/2014.

\begin{tabular}{lccccc}
\hline \multirow{2}{*}{ Matérias-primas } & \multicolumn{5}{c}{ Região } \\
\cline { 2 - 6 } & Norte & Nordeste & Centro-Oeste & Sudeste & Sul \\
\hline Óleo de Soja & $90,67 \%$ & $56,50 \%$ & $82,60 \%$ & $43,56 \%$ & $74,94 \%$ \\
Gordura Bovina & $9,33 \%$ & $20,79 \%$ & $11,71 \%$ & $52,55 \%$ & $23,61 \%$ \\
Óleo de Algodão & - & $22,57 \%$ & $3,84 \%$ & $1,60 \%$ & - \\
Outros Materiais Graxos & - & - & $0,79 \%$ & $0,13 \%$ & - \\
Óleo de Fritura usado & - & $0,14 \%$ & $0,97 \%$ & $2,16 \%$ & $0,60 \%$ \\
Gordura de Porco & - & - & $0,06 \%$ & - & $0,85 \%$ \\
Gordura de Frango & - & - & $0,03 \%$ & - & - \\
\hline
\end{tabular}

Fonte: ANP (2014).

Como colocado anteriormente, a soja predomina dentro da produção de biodiesel, outras matérias-primas que foram inicialmente planejadas com o intuito de facilitar a entrada da pequena produção acabaram não se desenvolvendo, dado a própria estrutura de mercado que predominou dentro do setor. O reflexo disto é o questionamento quanto a capacidade do PNPB atender o objetivo de geração de emprego e renda na agricultura familiar.

\subsection{Agricultura Familiar e desenvolvimento rural no PNPB}

O PNPB introduziu, além da questão energética do biodiesel e as demandas por mudanças nos padrões de uso energético no mundo, a missão de contribuir para o desenvolvimento rural pela produção de matérias-primas pela agricultura familiar, contribuindo para a geração de emprego e renda no meio rural, que possui um problema crônico e histórico de pobreza no Brasil e na América Latina (DE JANVRY; SADOULET, 2000; MOREIRA et al., 2009). O Selo Combustível Social proporciona vantagens competitivas dentro dos leilões e físcais (como a redução das alíquotas do PIS, PASEP e COFINS) para as empresas que cumprirem a aquisição mínima de matérias-primas da agricultura familiar para a produção de biodiesel.

Schultz (1965) emprega o conceito de agricultura tradicional para explicar a existência da pobreza e baixa renda no ambiente rural. Para ele, a agricultura tradicional é caracterizada por aquela que resiste a mudanças tecnológicas ocorridas no decorrer do tempo, logo sua 
produção é executada de formas muitas vezes rudimentares, acaba sendo incapaz de produzir muitos excedentes comercializáveis. Para tanto propõe que tal agricultura deve adotar novos "fatores" de produção, sejam insumos, sementes melhoradas, espécies mais resistentes, novas técnicas e equipamentos, para desta forma manter-se competitiva, soma-se ainda o fato da necessidade da disseminação do conhecimento, através da educação e extensão rural, pois também ao produtor é necessário dar o conhecimento sobre como utilizar os novos fatores, casos contrários tornam-se obsoletos. Esta colocação de Schultz é importante para compreender a dinâmica produtiva agrícola que existe no Mato Grosso e os desafios impostos a agricultura familiar quando esta pretende adentrar em um novo mercado, no caso, o biodiesel.

Em um recente estudo sobre a produção de matéria-prima para a produção de biodiesel em Tocantins pela agricultura familiar, Finco, Ribeiro e Bailis (2014) utilizaram um modelo logit para verificar os resultados do PNPB em relação a seus objetivos de inclusão social. Os autores verificaram que a política não esta sendo efetiva por não compreender os diversos interesses entre os agentes dentro da cadeia de produção do biodiesel. Muitas vezes conflitante, a produção de matéria-prima pela agricultura familiar e as aquisições das empresas produtoras de biodiesel pode levar a desvios na execução dos objetivos do programa em relação à inclusão social.

Outro estudo para o PNPB e a agricultura familiar a partir da análise da produção de matérias-primas nos estados da Bahia Ceará e Piauí é elaborada por Rathmann, Szklo e Schaeffer (2012). Os autores identificam a dificuldade desta em ser capaz de suprir a demanda das indústrias de biodiesel, portanto as grandes propriedades agrícolas, já integradas ao agronegócio, tendem a tomar espaço neste mercado. Colocam ainda que o resultado da iniciativa do PNPB é muitas vezes disfarçado por programas de transferência de renda, não ficando evidente qual parcela do desenvolvimento rural é proporcionada pela atividade produtiva. Ainda em relação ao agronegócio, Pousa, Santos e Suarez (2007) observaram bem que a pequena produção encontraria dificuldades para competir com a produção em larga escala, portanto o programa deveria oferecer maior assistência aos produtores com a oferta recursos, como crédito, assistência social e auxílios a sua organização na cadeia.

Casos de sucesso também são observados no PNPB, como o projeto Agropalma no Pará (CÉSAR; BATALHA, 2013). Embora em menor quantidade, outras oleaginosas, como o óleo de palma e a mamona, são utilizadas para a produção de biodiesel, e suas características produtivas podem favorecer a inclusão da agricultura familiar neste mercado, sendo uma alternativa a produção de soja. Finco e Doppler (2011) realizaram estudo acerca da estratégia de 
redução de pobreza pelo PNPB no estado de Tocantins com pequenos produtores, que produziam duas espécies diferentes, a mamona e o pinhão-manso obtiveram diferentes conclusões para as duas culturas. No caso da mamona foi notado que famílias pobres estavam sendo incluídas no Programa, enquanto que a probabilidade de inclusão no caso do pinhão-manso era menor. Nível educacional, condições de vida, acesso a serviços básicos e riscos climáticos foram destacados para a preferência das famílias por uma cultura de curto prazo como a mamona.

Mudar a base das oleaginosas utilizadas para a produção de biodiesel é colocada por Mendes e Cunha (2013). Além da sua menor eficiência como fonte de produção de biodiesel frente a outras possibilidades, ela é uma cultura que envolve condições de produção que dificultam a entrada de agricultores familiares neste segmento. Os investimentos em produtividade envolvem custos excessivos, que somente podem ser cobertos por agricultores familiares já capitalizados, reduzindo o sucesso do PNPB em atingir seu objetivo em integrar produtores ainda não vinculados ao mercado agrícola.

O desenvolvimento rural é objetivo do programa ao se criar mecanismos que possibilitem a geração de renda dentro da propriedade através do trabalho produtivo. A importância da iniciativa é corroborada por pesquisas que ligam o papel da agricultura com a redução da pobreza (DETHIER; EFFENBERGER, 2012), seja na pequena produção pela oferta direta de emprego e oportunidade de uso produtivo da terra, seja nas grandes propriedades pelo desenvolvimento econômico, oferta de produtos para a indústria e formação de capital para transferência para outros setores (JOHNSTON; MELLOR, 1961).

\section{METODOLOGIA}

Para concretização do objetivo estabelecido foi realiza uma pesquisa com 25 produtores rurais familiares que fornecem matérias-primas para uma usina de biodiesel localizada no município de Feliz Natal, norte de Mato Grosso. Os produtores estavam distribuídos entre os municípios de Vera (16 produtores), Tabaporã (5 produtores). Feliz Natal (3 produtores) e Nova Ubiratã (1 produtor), todos municípios de Mato Grosso e próximos ao município sede da usina.

Foram aplicados questionários semi-estruturados contemplando tanto questões objetivas como subjetivas, mas obedecendo a uma sequência lógica na obtenção das informações, permitindo ao mesmo tempo a interferência do pesquisador para acrescentar, questionar novos fatos e coletar outras informações necessárias para o entendimento do tema. 
Na realização dos procedimentos estatísticos e matemáticos para os métodos quantitativos foi utilizado o software Eviews7.

A partir da obtenção da receita dos produtores durante as três safras em que os mesmos forneceram matéria-prima para a produção de biodiesel (2010/2011, 2011/2012 e 2012/2013), foi realizada a estimação do lucro líquido de cada produção para cada safra a partir do custo de produção divulgado pela Aprosoja (2013) para os municípios de Sinop (considerados para o custo dos produtores em Feliz Natal, Tabaporã e Vera) e de Sorriso (considerado para os produtores de Nova Ubiratã). Como a produção é destinada para a mesma usina, os padrões de qualidade e quantidade são pré-estabelecidos e acompanhados pela assistência técnica da usina. Portanto, para mensurar outras variáveis que possam contribuir na formação da renda de cada produtor foi estimado um modelo de regressão linear por meio do método de Mínimos Quadrados Ordinários (MQO), conforme descrito na equação 1.

$$
\ln \bar{Y}_{i}=\alpha+\beta_{1} h_{i}+\beta_{2} s_{i}+\beta_{n} t_{i}+\beta_{4} t^{2}+\beta_{\mathrm{i}} c_{i \bar{i}}+\varepsilon_{i}
$$

Onde:

$\ln \bar{Y}_{i}=$ Logaritmo natural da renda média auferida pelos produtores familiares;

$h_{i}=$ área do produtor, em hectares;

$s_{i}=$ anos de estudo do produtor;

$t_{i}=$ anos de experiência na atividade;

$c_{i}=$ acesso ao crédito (PRONAF), sendo uma variável dicotômica;

$\varepsilon_{i}=$ termo de erro estocástico.

A partir modelagem proposta por Mincer (1974) onde se busca analisar os efeitos da educação e da experiência do produtor sobre os seus rendimentos, foi a adicionado duas variáveis ligadas a produção agrícola, a extensão da terra e o acesso ao crédito Programa Nacional de Fortalecimento da Agricultura Familiar (PRONAF). Espera-se que os coeficientes se apresentem positivos para todas as variáveis que se mostrarem significativas. Os valores financeiros utilizados foram atualizados para maio de 2013, através do uso do IPCA, dado que o objetivo é mensurar a renda familiar.

Buscando complementar a análise da produção de matérias-primas pela agricultura familiar no Norte de Mato Grosso, também foi realizado uma entrevista com os dirigentes da usina que adquire a produção para o Selo Combustível Social. Os principais pontos abordados 
foram a percepção da empresa frente ao objetivo programa e as vantagens e dificuldades existentes na negociação com a pequena produção familiar.

\section{RESULTADOS E DISCUSSÃO}

Este trabalho envolveu a pesquisa com 25 produtores rurais familiares no Norte do estado de Mato Grosso, distribuídos entre quatro municípios com características semelhantes quanto a sua estrutura produtiva agrícola, voltada principalmente para a produção de soja em larga escala dentro de um mercado altamente integrado. Todos os agricultores familiares entrevistados fornecem soja como matéria-prima para uma usina de biodiesel localizada no município de Feliz Natal através do Selo Combustível Social, portanto uma prática resultante do PNPB.

Foi possível inicialmente detectar uma particularidadequanto à titulação das terras dos produtores. Embora assentamentos possuam menor índice de sucesso em relação ao desenvolvimento de atividades produtivas, a maioria dos produtores (78\%) eram assentados da reforma agrária, enquanto que os demais tinham propriedade própria ou arrendada. A problemática da produção agrícola nos assentamentos no Mato Grosso foi analisada por Alves, Figueiredo e Zavala (2012), destacando as condições de infraestrutura existentes como uma das principais causas para a ineficiência produtiva dos assentados. Tais dificuldades foram evidenciadas na pesquisa, embora em menor intensidade. Todos os produtores tinham acesso à energia elétrica em suas propriedades, mas algumas estradas de acesso estavam em má condição de tráfego se comparadas às demais estradas vicinais, principalmente em relação às propriedades localizadas nos assentamentos onde a intensidade de fluxo, malha existente e frequência de serviços realizados pelo governo local varia constantemente, dificultando a sua conservação. O resultado é um problema logístico, seja no fluxo de pessoas ou de máquinas que são utilizadas para execução dos serviços de plantio e colheita nas propriedades familiares.

As receitas individuais para cada safra foram obtidas junto aos produtores, a partir da obtenção do custo de produção de soja em Mato Grosso (APROSOJA, 2013), foi possível realizar uma estimativa do lucro do plantio de soja na agricultura familiar. Importante destacar o papel do bônus de aquisição de $\mathrm{R} \$ 1,20$ por saca de soja que é pago aos produtores rurais. Este valor contribui para a formação individual da renda ao compensar parcialmente as flutuações de preço da soja no mercado, reduzindo as incertezas dentro da produção de commodities.

ReFAE - Revista da Faculdade de Administração e Economia, v. 8, n. 2, p. 172-188, 2017 
Com a renda individual calculada foi possível verificar quais outras variáveis podem afetar a diferença de lucro entre os produtores rurais além apenas dos custos de produção. A partir da proposta de Mincer (1974) em considerar os efeitos da educação e da experiência como determinantes da renda, foram adicionadas duas variáveis ligadas a característica produtiva, uma é a área total cultivada em soja e a segunda é a obtenção de crédito PRONAF. Os resultados obtidos estão descritos na Tabela 3.

Tabela 3: Resultados obtidos por mínimos quadrados ordinários na verificação da geração de renda para os produtores pesquisados.

\begin{tabular}{lcccc}
\hline Variáveis & Coeficientes & $\mathbf{t}$ & Desvio Padrão & Significância \\
\hline Constante & 9,47652 & 0,2387 & 39,7023 & 0,0001 \\
Área cultivada & 0,01696 & 0,0034 & 4,9418 & 0,0001 \\
Estudo & 0,01556 & 0,0329 & 0,4728 & 0,6417 \\
Experiência & $-0,00054$ & 0,0012 & $-0,4537$ & 0,6552 \\
Experiência quadrado & $-0,00047$ & 0,0193 & $-0,0243$ & 0,9808 \\
Acesso ao crédito & 0,06575 & 0,1010 & 0,6509 & 0,5229 \\
\hline Número Observações & 25 & & & \\
$\mathbf{R}^{2}$ & 0,6272 & & & \\
Teste F (significância) & $6,3918(0,0012)$ & & & \\
\hline
\end{tabular}

Fonte: Elaborado pelo autor a partir dos resultados da pesquisa.

Não foi detectada a presença de autocorrelação entre os termos de erro através do uso do Teste Durbin-Watson. Também foi confirmada a hipótese de homocedasticidade para a variância do termo de erro pelo uso do Teste de White. A estatística F demonstrou que os parâmetros estimados não são simultaneamente iguais a zero, embora individualmente possam apresentar não significância estatística pelo teste t, que será discutida a seguir.

A partir dos resultados obtidos (tabela 3) percebe-se que as variáveis estudo, experiência e crédito não apresentaram significância estatística. Apenas a área cultivada e a constante tiveram significância. Em relação à proposta de Mincer pelo conhecimento e experiência contribuírem para a geração de renda, a produção de soja possui uma sistemática diferenciada em relação ao aproveitamento deste conhecimento individual. Sendo um mercado altamente verticalizado, os preços são formados sem a interferência destes produtores, a capacidade de negociação é reduzida. A oferta de assistência técnica obrigatória atua como um processo padronizador da produção entre os produtores rurais, convergindo em 
formas de produção, uso dos recursos e insumos e produtividade. A constante positiva representa estas situações que são comuns entre os diversos produtores rurais, garantindo que a produtividade tende a convergir para a mesma dado as aplicações similares de insumos, técnicas de plantio e colheita, além de negociação de preços e de custos. Diferenças entre os produtores acabam por resultar principalmente de sua diferença de área, tendo como resultado maior produção total de soja e consequentemente maior renda.

$\mathrm{O}$ acesso ao crédito não ocorre de forma uniforme, apenas 14 produtoresafirmaram receber crédito do PRONAF, dentre estes, 11 são assentados da reforma agrária, portanto seus limites financeiros para investir na propriedade por meio do crédito rural são baixos, não contribuindo para o desenvolvimento da produção de soja, que requer maiores volumes de aplicação por extrato de área. Esta situação demonstra porque o crédito rural não apresentou significância estatística, sendo outras formas de financiamento, como o financiamento direto pelas tradings mais vantajosas para os produtores. A política de fomento da produção de matéria-prima pelo PNPB não ofereceu mecanismos suficientes para viabilizar a diversidade produtiva na agricultura familiar a partir das informações obtidas neste trabalho, ficando os produtores dependentes dos instrumentos de mercado para a execução das atividades. Tais mecanismos podem ser limitadores pelas capacidades técnicas e produtivas dos diversos produtores existentes no meio rural brasileiro e mato-grossense.

Observa-se também que, como a soja é uma cultura de ganhos de escala, os produtores que possuem maiores extratos de terra (e, portanto, cultivam em maior área), obtém também maiores receitas. Assim, dentro da própria agricultura familiar, existe uma diferença de rendimentos baseada principalmente na extensão das terras, haja vista que as técnicas de cultivo são similares entre os produtores. Este uso total da terra para o plantio de soja é uma forma de maximizar os ganhos obtidos na propriedade, entretanto levanta novas questões sobre a pressão que a soja exerce sobre o meio ambiente (BROWN et al., 2005; FEARNSIDE, 2001), principalmente por estes produtores estarem localizados no bioma Amazônia.

A proposta do PNPB em substituir fontes não-renováveis de energia por fontes renováveis e menos emissoras de gases que possam contribuir para o efeito estufa encontra no monocultivo extensivo da soja pela agricultura familiar um paradoxo (HOUTART, 2010), dado que esta necessita "eliminar" a floresta nativa para o plantio. Alternativas, como o aproveitamento de áreas degradadas ou abandonadaspodem ser saídas para aumentar a produção, integrar novas famílias e não utilizar da floresta nativa como forma de expansão da atividade agrícola (CAMPBELL et al., 2008). Outros temas controversos, como a mudança no 
uso da terra pela substituição do cultivo de alimentos para a produção de energia (através da oferta de matérias-primas), são colocados em debate. Para a agricultura familiar, como notado neste estudo em Mato Grosso, a terra foi destinada completamente para a produção de uma commoditie agrícola. Sendo a agricultura familiar a principal fornecedora de alimentos, o Programa estaria incentivando a mudança produtiva por um número maior de produtores, entretanto pelas limitações observadas no acesso da agricultura familiar a produção de soja, esta situação ainda está longe de ser observada. O desenvolvimento de novas gerações de biocombustíveis pode vir a solucionar ambos os problemas, com a possibilidade de novas culturas sendo integradas na produção de biocombustíveis e com a menor demanda por área e pressão sobre a produção de alimentos (GRAHAM-ROWE, 2011).

Foi possível identificar que a geração de renda para a agricultura familiar através do plantio de soja requer alguns determinantes. O investimento em capital fixo é reduzido, aquisições de máquinas pesadas e equipamentos são restritos a alguns itens, como tratores e pulverizadores de pequeno porte. Colheitadeiras, plantadeiras e outras máquinas são arrendadas de prestadores de serviço da região. Serviços de arrendamentos são negociados conforme a área a ser colhida, resultando em menores custos para o produtor, tanto por deter uma área menor como também por significar menor exigência em desembolso imediato de capital, dado que os limites de financiamento no PRONAF não atendem tal demanda (principalmente para os Assentados). Alguns produtores detinham tais equipamentos, embora de fabricação antiga resultante de sua aquisição em anos anteriores, estes eram capazes de executar o reduzido serviço demandado em pequenas propriedades. Embora a experiência e estudo não tenham apresentado significância, cabe ao produtor desenvolver novas técnicas de gestão de sua propriedade, como esta forma de substituição da necessidade de capital fixo pelo arrendamento de maquinários. Como colocado por Schultz (1965), insumos modernos devem ser aplicados na pequena produção, entretanto devem estar condizentes com as características de capital e poupança destes produtores.

As especificações de qualidade de entrega do produto seguem o mesmo formato a todos os produtores. A prestação de assistência técnica para os produtores familiares é uma exigência legal do PNPB e é oferecida pela usina, que por sua vez orienta os produtores nautilização de insumos, produtos e sementes especificadas para o plantio da soja, atendendo a demanda da empresa pela matéria-prima e dos produtores com uma produção satisfatória, onde a produtividade média alcançada entre os produtores considerando as três safras analisadas foi de 52 sacas por hectares. A Tabela 4 traz um resumo dos resultados financeiros obtidos pelos produtores nas safras pesquisadas. 
Tabela 4: Lucro estimado a partir da receita total* para os produtores rurais familiares (em $\mathrm{R} \$)$.

\begin{tabular}{lccc}
\hline & Safra 2010/2011 & Safra 2011/2012 & Safra 2012/2013 \\
\hline Lucro Máximo** $^{*}$ & $59.026,60$ & $46.344,37$ & $75.557,55$ \\
Lucro Mínimo** $^{*}$ & $20.148,73$ & $17.379,14$ & $10.157,30$ \\
Lucro Médio** $^{*}$ & $27.116,95$ & $29.181,76$ & $48.443,62$ \\
\hline
\end{tabular}

Fonte: Resultados da pesquisa.

* Os valores foram atualizados para maio de 2013 com base no IPCA.

** Valores estimados a partir da consideração dos custos médios para Sorriso e Sinop.

O aumento do rendimento e lucro médio estimado para a safra de 2011/2012 se deu principalmente pelo aumento do preço da soja no período, que se estendeu até a safra 2012/2013, embora os custos para esta última safra tenham aumentado em relação a anterior (perceptível pela queda do lucro mínimo obtido por um produtor). Portanto os produtores também estão sujeitos a variações nos preços do produto e também em mudanças nos custos de produção. Como são um segmento com menor poder econômico e disponibilidade de capital, variações significativas quanto à redução do preço da soja podem impactar diretamente na viabilidade da cultura e na geração de renda, novamente se destaca a importância de que o PNPB possa dar maior suporte em relação a incerteza enfrentada pelos pequenos produtores rurais. De uma forma geral, para os produtores pesquisados e já integrados ao mercado de biodiesel, o programa atendeu a seu objetivo de geração de renda, embora ainda conte com diferenças entre as rendas obtidas (percebida pela diferença entre os lucros máximos e mínimos). Outro destaque importante é que em nenhuma safra estudada houve riscos climáticos ou ataques de pragas que causaram perdas significativas. Tais riscos podem representar uma situação desfavorável à continuidade da atividade pelos produtores caso venham a ocorrer, dado a dificuldade posterior no pagamento dos custos de produção, devendo ser contemplados dentro das políticas de auxílio à produção com a elaboração de novos instrumentos, como seguros de safra.

Além da pesquisa junto aos produtores, também foi realizada uma entrevista com os dirigentes da usina de biodiesel que adquire a produção da agricultura familiar. Uma informação levantada foi a dificuldade em encontrar agricultores familiares que produzem soja para a usina conseguir atender o mínimo necessário para manutenção do Selo Combustível Social. Destaca-se ainda que o PNPB planejou uma iniciativa interessante em integrar a pequena produção no programa, mas não conseguiu realmente oferecer condições 
suficientes para que estes produtores conseguissem desenvolver seus cultivos para atender a demanda por biodiesel, sendo que para superar estes problemas a usina tinha de oferecer vantagens para os produtores que forneciam matéria-prima.

Como o Mato Grosso é o maior produtor de biodiesel, também ali é encontrada maior quantidade de usinas produtoras. Pelas vantagens competitivas conferidas pelo Selo, existe uma intensa "disputa" para manter os produtores familiares que conseguem produzir a soja como fornecedores para a empresa. No caso estudado neste trabalho, os dirigentes destacaram que além da assistência técnica e do bônus de aquisição de $\mathrm{R} \$ 1,20$, que são obrigatórios por força de lei, a empresa também oferece alguns insumos (como calcário) para auxiliar na produção do grão e manter o produtor como fornecedor exclusivo para a empresa, embora ela enfrente dificuldades para manter esta vantagem ao produtor, uma vez que os concorrentes também passam a disputar os produtores familiares e oferecem outras vantagens. Esta foi uma desvantagem citada, pois a empresa deve oferecer a assistência técnica, vantagens legais e adicionais para os produtores, o que eleva os custos e reduz a rentabilidade da produção de biodiesel.

Esta "corrida" pelos produtores familiares demonstra parcialmente a dificuldade ainda existente para a produção de soja neste segmento rural. A existência de um paradigma produtivo de larga escala ainda é existente na produção agrícola mato-grossense. O PNPB não sendo efetivo em estimular a utilização de outras culturas mais viáveis para o pequeno produtor produzir, acabou por selecionar apenas aqueles se apresentavam mais capitalizados, capazes de produzir a soja em sua propriedade ao mesmo tempo em que obtém um retorno satisfatório sobre esta produção.

\section{CONCLUSÕES}

Uma nova configuração no setor rural mato-grossense pode estar em desenvolvimento, embora recente, esta mudança no paradigma produtivo da pequena produção pode criar futuras alternativas para a superação da pobreza no meio rural além de viabilizar a entrada de novos participantes no mercado de biodiesel. Entretanto esta mudança requer maior empenho das políticas públicas de incentivo a pequena produção, onde a oferta de crédito com valores e condições mais adequadas a este tipo de produção pode ter um efeito favorável, contribuindo para seu desenvolvimento.

Compreender a produção de soja pela agricultura familiar envolve novas pesquisas que possam analisar o arranjo institucional que vem se formando na região. Esta pesquisa 
demonstrou que as condições de mercado e de eficiência produtiva na soja ainda são determinantes para a geração de renda. Variáveis como preço e tamanho de área possuem peso significativo em um mercado altamente atrelado e verticalizado. O primeiro é determinado externamente ao produtor, portanto o bônus por saca contribui na manutenção da rendafrente às oscilações do mercado, enquanto que o segundo é um aspecto limitante na extensão da produção, neste ponto a assistência técnica, melhores condições de crédito e novas estratégias de gestão de custo podem auxiliar no aumento da produtividade e redução de custos, impactando diretamente no lucro. Os produtores entrevistados nesta pesquisa tiveram sucesso na geração de renda a partir da produção de matéria-prima para o biodiesel, mas o sucesso do PNPB é limitado pelo seu alcance, que conseguiu integrar uma parcela ainda reduzida do montante de agricultores que potencialmente podem fazer parte deste programa, confirmando para os casos estudados a hipótese estabelecida.

Novas questões surgem dentro do contexto da produção de soja estimulada pelo PNPB. Como um grão que vem aumentando sua produção frente à demanda nacional e mundial, a soja causa pressão sobre a conservação do meio ambiente. Os municípios estudados neste trabalho fazem parte do bioma Amazônia, portanto encontram um conflito entre a produção e geração de renda na agricultura familiar e a necessidade de abertura de áreas na floresta nativa para viabilizar e expandir esta produção. Trabalhos futuros podem contribuir em analisar este risco ambiental frente às mudanças institucionais necessárias dentro do PNPB.

\section{REFERÊNCIAS}

ALVES, J.; FIGUEIREDO, A. M. R.; ZAVALA, A. A. Z. (In)Eficiência dos Assentamentos Rurais em Mato Grosso. Cuiabá: EdUFMT, 2012. p. 186

ANDERSEN, L. E. et al. The dynamics of deforestation and economic growth in the Brazilian Amazon. New York: Cambridge University Press, 2002. p. 259

ANP. Anuário Estatístico Brasileiro do Petróleo, Gás Natural e Biocombustíveis - 2014. Disponível em: <http://www.anp.gov.br>. Acesso em: 11 mar. 2015.

APROSOJA. Custos de Produção da Soja. Disponível em: <http://www.aprosoja.com.br>. Acesso em: 9 jul. 2013.

BRASIL. Lei no 11.097, de 13 de Janeiro de 2005. Dispõe sobre a introdução do biodiesel na matriz energética brasileira; altera as Leis $n^{\circ}$ 9.478, de 6 de agosto de 1997, 9.847, de 26 de outubro de 1999 e 10.636, de 30 de dezembro de 2002; e dá outras providências. Brasília, DF: Diário Oficial [da República Federativa do Brasil], 2005.

ReFAE - Revista da Faculdade de Administração e Economia, v. 8, n. 2, p. 172-188, 2017 
BROWN, J. C. et al. Soybean production and conversion of tropical forest in the Brazilian Amazon: the case of Vilhena, Rondônia. Ambio, v. 34, n. 6, p. 462-469, 2005.

CAMPBELL, J. E. et al. The Global Potential of Bioenergy on Abandoned Agriculture Lands. Environmental Science \& Technology, v. 42, n. 15, p. 5791-5794, 2008.

CÉSAR, A. D. S.; BATALHA, M. O. Brazilian biodiesel: The case of the palm's social projects. Energy Policy, v. 56, p. 165-174, 2013.

DE JANVRY, A.; SADOULET, E. Rural poverty in Latin America determinants and exit paths. Food Policy, v. 25, p. 389-409, 2000.

DETHIER, J.-J.; EFFENBERGER, A. Agriculture and development: A brief review of the literature. Economic Systems, v. 36, n. 2, p. 175-205, 2012.

FEARNSIDE, P. M. Soybean cultivation as a threat to the environment in Brazil. Environmental Conservation, v. 28, n. 1, p. 23-38, 2001.

FINCO, M. V. A.; DOPPLER, W. The Brazilian Program of Biodiesel and its "Pro-Poor" Strategy: Reality or Dream? A Multi-Dimensional Measurement of Poverty using Fuzzy Sets. Quarterly Journal of International Agriculture, v. 50, p. 133-154, 2011.

FINCO, M. V. A.; RIBEIRO, V. S.; BAILIS, R. Biocombustíveis e a economia verde inclusiva: buscando o desenvolvimento regional sustentável na Amazônia legal brasileira. REDES, v. 19, n. 2, p. 130-153, 2014.

GRAHAM-ROWE, D. Agriculture: Beyond food versus fuel. Nature, v. 474, p. S6-S8, 2011.

HOLANDA, A. O biodiesel e a inclusão social. Brasília: Centro de Documentações e Informações, Câmara dos Deputados, 2003.

HOUTART, F. A agroenergia: solução para o clima ou saída da crise para o capital?. Petrópolis: Editora Vozes, 2010.

JOHNSTON, B. F.; MELLOR, J. W. The Role of Agriculture in Economic Development. The American Economic Review, v. 51, n. 4, p. 566-593, 1961.

LIMA, S. M. V; CASTRO, A. M. G. A Agroindústria de Óleo Vegetal para a Produção de Biodiesel. In: CASTRO, A. M. G.; LIMA, S. M. V; SILVA, J. F. V (Eds.). Complexo Agroindustrial de Biodiesel no Brasil: Competividade das Cadeias Produtivas de Matérias-Primas. Brasília: Embrapa Agroenergia, 2010. p. 712.

MENDES, A.; CUNHA, R. Mercado brasileiro de biodiesel e perspectivas futuras. BNDES Setorial, v. 31, p. 253-280, 2013.

MINCER, J. Schooling, experience, and earning. New York: Comlumbia University Press, 1974. 
MOREIRA, R. C. et al. Políticas públicas, distribuição de renda e pobreza no meio rural brasileiro no período de 1995 a 2005. Revista de Economia e Sociologia Rural, v. 47, n. 4, p. 919-944, 2009.

OSAKI, M.; BATALHA, M. O. Produção de Biodiesel e Óleo Vegetal no Brasil: Realidade e Desafio. Organizações Rurais \& Agroindustriais, v. 13, n. 2, p. 227-242, 2011.

POUSA, G. P. A G.; SANTOS, A. L. F.; SUAREZ, P. A Z. History and policy of biodiesel in Brazil. Energy Policy, v. 35, p. 5393-5398, 2007.

RATHMANN, R.; SZKLO, A.; SCHAEFFER, R. Targets and results of the Brazilian Biodiesel Incentive Program - Has it reached the Promised Land? Applied Energy, v. 97, p. 91-100, 2012.

RODRIGUES, M.; MARQUEZIN, W. R. CPR como um instrumento de crédito e comercialização. Revista de Política Agrícola, v. 23, n. 2, p. 40-50, 2014.

SCHULTZ, T. W. A Transformação da agricultura tradicional. Rio de Janeiro: Zahar, 1965. 